\title{
Effectiveness of ground based walking with relaxation techniques to improve the quality of life in patients with chronic obstructive pulmonary disease
}

\begin{abstract}
Objectives: The aim of the study is to determine the effectiveness of ground based walking with relaxation techniques to improve the quality of life in patients with COPD.

Methodology: Participants were randomized into two groups. In experimental group patients received ground based walking and relaxation techniques. In control group patients received only relaxation techniques .Pre test and post test evaluation is done using the Borg's Scale and Clinical COPD Questionnaire.

Results: There is significant improvement in patients with COPD who received ground based walking and relaxation techniques when compared with the patients received relaxation techniques alone.

Conclusion: The present study proved that the both ground based walking and relaxation techniques are effective in improving the quality of life in patients with COPD than the relaxation techniques alone.
\end{abstract}

Keywords: chronic obstructive pulmonary disease, ground based walking, relaxation techniques, borg's scale, clinical copd questionnarrie
Volume 3 Issue 4 - 2018

\author{
Muthukumar TS,' Monisha $\mathrm{R},{ }^{2}$ Binitha Serin \\ Babu, ${ }^{3}$ Mohankumar Thekkinkatil ${ }^{4}$ \\ 'Department of Cardio-Respiratory Physiotherapy, College of \\ Physiotherapy S.R.I.P.M.S, India \\ ${ }^{2}$ SRM College Of Physiotherapy, SRM Institute of Science and \\ technology, India \\ ${ }^{3}$ Undergraduate Physiotherapy Student, College of \\ Physiotherapy S.R.I.P.M.S, India \\ ${ }^{4}$ Chief Consultant and H.O.D Institute of Pulmonary Medicine, \\ and Research Sri Ramakrishna Hospital, India
}

\begin{abstract}
Correspondence: Muthukumar TS, Professor and H.O.D, Department of Cardio-Respiratory Physiotherapy, College of Physiotherapy S.R.I.P.M.S, Coimbatore, Tamilnadu, India, Email muthukumarphysio@gmail.com
\end{abstract}

Received: July 22, 2018 | Published: September 21, 2018
Abbreviations: COPD, chronic obstructive pulmonary disease; $\mathrm{CCQ}$, clinical copd questionnarrie

\section{The background}

Chronic obstructive pulmonary disease is used to describe resistance to airflow that is associated mainly with Emphysema and Chronic bronchitis. The majority of the patient's complaint is dyspnea due to expiratory air flow limitation and high respiratory rate affecting quality of life. This may lead to limitations in functional activities. ${ }^{1}$

Pulmonary rehabilitation is recognized as an essential component of the management of Chronic Obstructive Pulmonary Disease. Ground based walking is one such mode of training. Walking significantly improves walking capacity and quality of life for patients with COPD.

Walking is a low impact exercises places minimum stress on the joint and is generally an easy exercise for Chronic Obstructive Pulmonary Disease patients to perform. Walking helps to build the muscle endurance, improve well being and allow becoming more selfsufficient. The relaxation technique helps to improve the quality of life and also reduce the dyspnea, as well as improving their physical activity. Breathing exercises help people to breathe more effectively and efficiently. The progressive muscle relaxation is an effective treatment in people with chronic obstructive pulmonary disease. It is a therapy that focuses on tightening and relaxing the muscle. The progressive muscle relaxation reduces anxiety and dyspnea as well as reduces intensity of pain, and relieves stress in patients with Chronic Obstructive Pulmonary Disease. ${ }^{2}$
The use of ground based walking with relaxation techniques in patients with chronic obstructive pulmonary disease to relieve dyspnea and anxiety level, still remains to be optimized. Hence the study aims in contributing towards the Efficacy of ground based walking and relaxation techniques in patients with Chronic Obstructive Pulmonary Disease. $^{3-8}$

\section{Methodology}

The study was conducted on patients admitted in the Department of Pulmonology and Critical care, Sri Ramakrishna Hospital and referred for physiotherapy treatment. Non probability randomized sampling method was used to allocate the samples into two groups. ${ }^{9-15}$

\section{Inclusion criteria}

a. Moderate chronic obstructive pulmonary diseases of age group of 50-60years

b. Severe chronic obstructive pulmonary diseases of age group of 50-60years

\section{Exclusion criteria}

a. Unstable cardiac disease

b. Long term oxygen therapy

c. Inability to complete exercise training

d. Osteoarthritis

e. Body mass index $>35 \mathrm{~kg}$ 


\section{Group A (Experimental group):}

In this patients underwent ground based walking with relaxation techniques under supervision.

\section{Group B (Control group)}

In this group patients underwent relaxation techniques such as breathing exercises and progressive muscle relaxation techniques.

\section{Study protocol}

In the walking group patients were encouraged to walk on a $20 \mathrm{~m}$ track with their own pace for 15 minutes with adequate rest periods for 15days with 5days a week in Pulmonary Rehabilitation department. Relaxation training for 15 minutes was given before and after the walk. The standardized termination criteria was adopted. In the control group the patients were encouraged to do relaxation techniques such as progressive muscle relaxation exercises and breathing exercises for 15 minutes daily for 15 days. In both the group, the patients were supervised by a treating physiotherapist. ${ }^{15-18}$

\section{Parameters}

The following parameters were used to record the parameters.

a. Borg's scale

b. Clinical COPD Questionnaire (CCQ) ${ }^{2}$

\section{Statistical tools}

Independent " $t$ " test was used to show the effectiveness of treatment between group A and group B (Graphs 1-5).

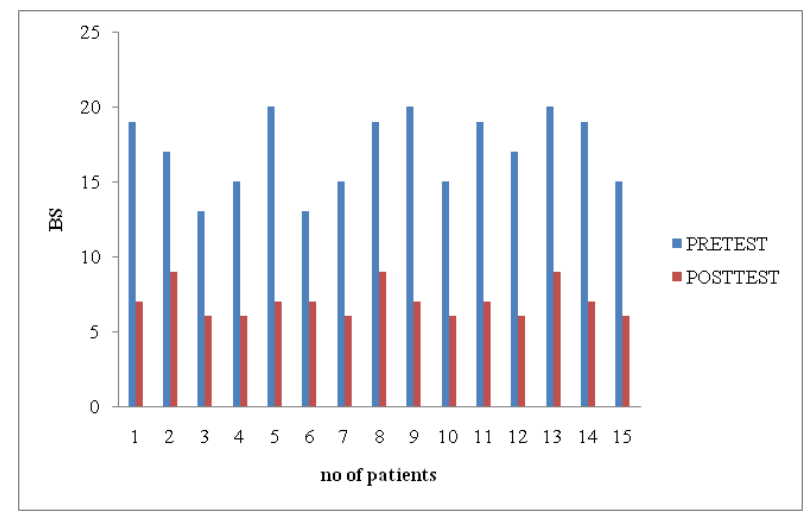

Graph I Borg's Scale For Group A.

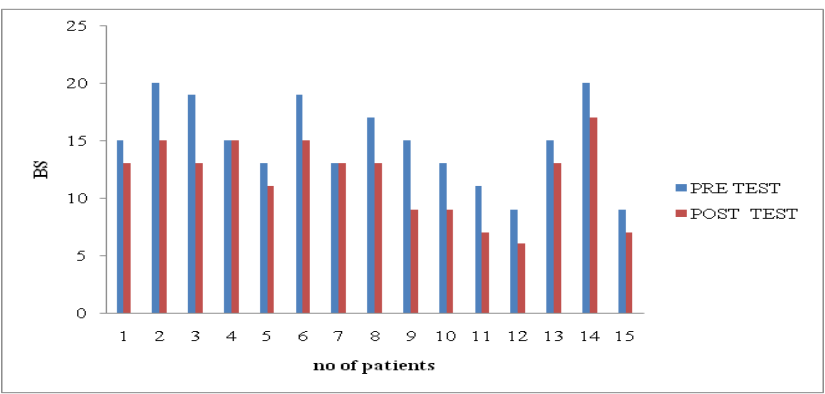

Graph 2 Borg's Scale For Group B.

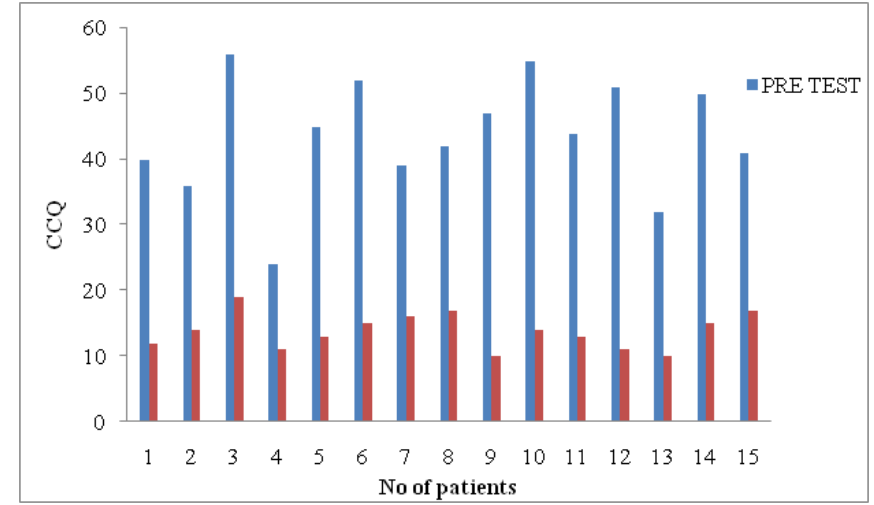

Graph 3 Clinical COPD questionnaire Group A.

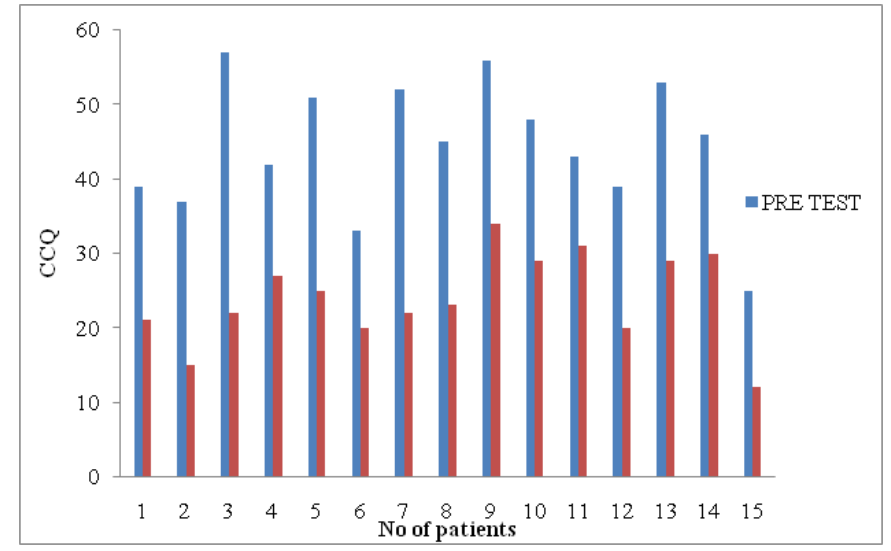

Graph 4 Clinical COPD questionnaire Group B.

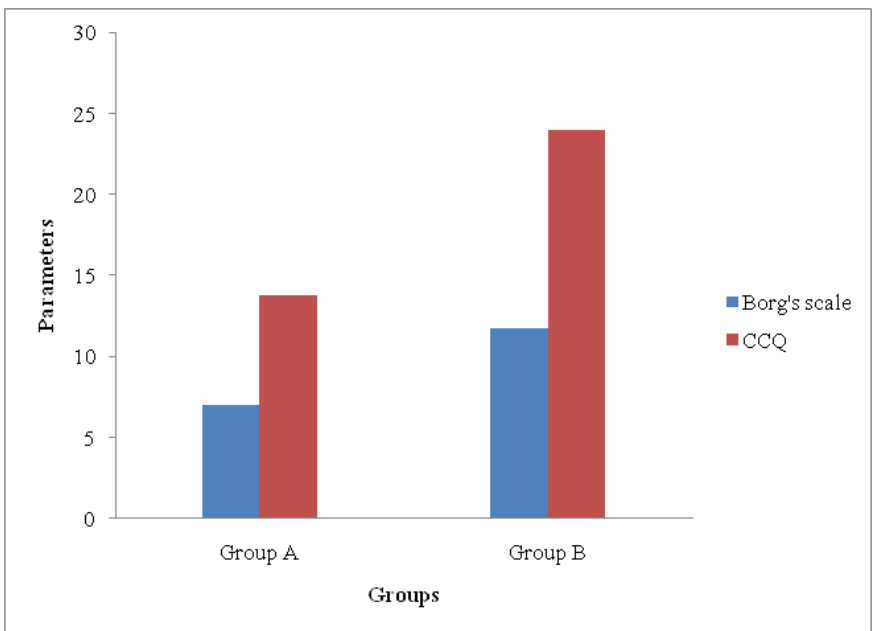

Graph 5 Mean difference between group a group b for borg's scale and clinical COPD questionnaire.

\section{Discussion}

This is a comparative study in which the objective is to determine "The effectiveness of ground based walking with relaxation techniques to improve quality of life in patients with chronic 
obstructive pulmonary disease." The purpose of study is that there is significant improvement in quality of life and reduction of anxiety level in patients with chronic obstructive pulmonary disease. In each group Borg's scale and Clinical COPD Questionnaire (CCQ) are used.
The Borg's scale is used to identify the reduction of dyspnea level and CCQ is used to measure the health status in patients with chronic obstructive pulmonary disease (Table 1).

Table I Standard deviation between group a group b for borg's scale and clinical COPD questionnaire

\begin{tabular}{lllll}
\hline Parameters & Group & Mean difference & Standard deviation & Calculated 't' value \\
\hline \multirow{2}{*}{ Borg's Scale } & Group A & 7 & 2.474 & \\
& Group B & 11.73 & & \\
Clinical COPD questionnaire & Group A & 13.8 & 4.12 \\
& Group B & 24 & 5.914 \\
\hline
\end{tabular}

Using Borg's scale, in Group A there is maximum improvement in 2 patients, moderate improvement in 10 patients and minimum in 1 patient. In Group B there is moderate improvement in 7 patients and moderate improvement in 6 patients and no improvement in 2 patients. Using Clinical COPD Questionnaire (CCQ), in Group A there is maximum improvement in 1 patients, moderate improvement in 5 patients and minimum improvement in 3 patients. In Group B there is moderate improvement in 1 patient and minimum improvement in 4 patients. The ground walking and the relaxation techniques play an important role in dyspnea reduction and also reduces the anxiety and improves health status in patients with chronic obstructive pulmonary disease. Hence based on the information presented, the independent ' $t$ ' test was performed to analyze the results. The calculated ' $T$ ' value for Borg's scale 5.1278 and CCQ is 5.9153, which is greater than the table value of 2.048 in accordance to the level of significance of 0.05 .

\section{Conclusion}

Based on the outcome of the statistical analysis and literature review, it is believed that the ground based walking with relaxation techniques shows significant improvement in people with chronic obstructive pulmonary disease. It is definitely advantageous in reducing the symptoms in patients with chronic obstructive pulmonary disease. "There is significant improvement in respiratory parameters, functional improvement and improvement in the quality of life in chronic obstructive pulmonary disease patients given with ground based walking with relaxation techniques than the relaxation techniques alone."

\section{Acknowledgements}

None.

\section{Conflict of interest}

The author declares no conflict of interest.

\section{References}

1. Access Economics Pty Limited. Economic impact of COPD and cost effective solutions. The Australian Lung Foundation. 2008.

2. Ayalu A. The study shows the reliability and validity of the clinical COPD questionnaire and chronic respiratory questionnaire. 2010.

3. Aydin IO, Ulusahin A. Depression and anxiety, co morbidity and disability in tuberculosis and chronic obstructive pulmonary diseases. Gen Hosp Psychiatr. 2001;23(2):77-83.

4. Bednarek M, Maciejewski J, Wozniak M, et al. prevalence, severity and under diagnosis of Chronic Obstructive Pulmonary Disease in the primary care setting. Respiratiry Medicine. 2008;4(3):103.

5. Beeh KM, Watz H, Puente-Maestu L, et al. Aclidinium improves exerciseendurance, dyspnoea, lung hyperinflation, and physical activity in patients with COPD: a randomized, placebo-controlled, crossover trail. BMC Pulm Med. 2014

6. Berkhof FF, Metzemaekers L, Uil SM, et al. Health Status in patients with COPD and Heart failure: A validation and comparison between the clinical COPD questionnaire and the Minnesota living with heart failure questionnaire. Int J Chron Obstruct Pulmon Dis. 2014;9:999-1008.

7. Eakin E G. The study conducted based on the measurement of dyspnoea using Borg Scale in chronic obstructive pulmonary disease. JSTOR. 1993;2(3):181-191.

8. Global Initiative for Chronic Obstructive Pulmonary Disease (GOLD). Global strategy for the diagnosis, management, and prevention of Chronic Obstructive Pulmonary Disease. 2008.

9. Gretchen A, Brenes. Anxiety and Chronic Obstructive Pulmonary Disease: Prevalence, Impact, and Treatment. 2003.

10. He M. Efficiency and safety of pulmonary rehabilitation in acute exacerbation of chronic obstructive pulmonary disease. Med Sci Monit. $2015 ; 21: 806-812$.

11. Kendrick KR, Baxi SC, Smith RM. The study shows that usefulness of the modified 0-10 Borg Scale in assessing the degree of dyspnea in patients with COPD and Asthma. J Emerg Nurs. 2000;26(3):216-222.

12. Maltais F, LeBlanc P, Simard C, et al. skeletal muscle adaptation to endurance training in patients with Chronic Obstructive Pulmonary Disease. Am J Respir Crit Care Med. 1996;154(2 Pt 1):442-447.

13. Ställberg B, Nokela M, Ehrs PO, et al. Validation of clinical COPD questionnaire (CCQ) in primary care. Health Qual Life Outcomes. 2009;7:26.

14. Renfroe KL. Effect of progressive relaxation on dyspnoea and state of anxiety in patients with Chronic Obstructive Pulmonary Disease. Heart Lung. 1988;17(4):408-413.

15. Revill SM, Morgan MD, Singh SJ, et al. The endurance shuttle walk: a new field test for the assessment of endurance capacity in Chronic Obstructive Pulmonary Disease. Thorax. 1999;54(3):213-222. 
16. Singh SJ, Morgan MD, Scott S, et al. Development of a shuttle walking test of disability in patients with Chronic Obstructive Pulmonary Disease. Thorax. 1992;47(12):1019-1024

17. S Watts, ZMckeough, S Jenkins, et al. Effects of ground walking training in Chronic Obstructive Pulmonary Disease: A Randomised Trial Control. 2008 .
18. Troosters T, Gosselink R, Decramer M. Six minute walking distance in healthy elderly subjects. European Respiratory Journal. 1999;14(2):270 274 